\title{
PERANCANGAN MERCHANDISE GUNA MENUNJANG EFEKTIVITAS PROMOSI
}

\author{
Adi Kusuma Widya Tama ${ }^{1}$ \\ Maria Dingi Novena ${ }^{2}$ \\ Sefty Lestari ${ }^{3}$ \\ Dosen STMIK Raharja ${ }^{1}$ \\ STMIK Raharja Jurusan Teknik Informatika ${ }^{2,3}$ \\ Jl. Jenderal Sudirman No. 40, Moderland Tangerang ${ }^{1,2,3}$ \\ Email : adi.kusuma@raharja.info ${ }^{1}$,maria@raharja.info ${ }^{2}$, sefty@raharja.info ${ }^{3}$
}

\begin{abstract}
ABSTRAK
Merchandise adalah bentuk produk yang ditujukan sebagai sarana informasi dan promosi. Sekolah Tinggi Ilmu Tarbiyah (STIT) Islamic Village Tangerang merupakan lembaga pendidikan Perguruan Tinggi yang berorientasi pada pengembangan ilmu-ilmu pendidikan. Setiap tahunnya di Sekolah Tinggi Ilmu Tarbiyah (STIT) Islamic Village Tangerang membuka pendaftran bagi calon mahasiswa dan mahasiswi baru, yang menjadi permasalahan saat ini yaitu media promosi dan informasi yang digunakan oleh Sekolah Tinggi Ilmu Tarbiyah (STIT) Islamic Village Tangerang masih belum maksimal, seperti belum tersedianya media merchandise. Sehingga Sekolah Tinggi Ilmu Tarbiyah (STIT) Islamic Village Tangerang membutuhkan media merchandise berupa Pin, Sticker, Mug, Topi, Shopping Bag, Kalender, Payung, dan Pulpen. Penelitian ini menggunakan software Adobe Illustrator CS6 yang merupakan program penunjang desain. Desain yang menarik sangat membantu untuk memaksimalkan fungsi merchandise sebagai media informasi dan promosi. Informasi adalah pesan yang ingin disampakan baik secara langsung maupun secara visual. Promosi itu sendiri adalah suatu cara untuk memberitahukan kepada msyarakat umum agar dapat tertarik untuk bergabung dengan Sekolah Tinggi Ilmu Tarbiyah (STIT) Islamic Village Tangerang. Metodologi penelitiannya yaitu metode pengumpulan data dan konsep desain. Dapat kita simpulkan kegiatan penelitian ini memiliki maksud dan tujuan untuk membuat desain media informasi berupa merchandise yang diharapkan dapat meningkatkan citra dan minat untuk bergabung dengan Sekolah Tinggi Ilmu Tarbiyah (STIT) Islamic Village Tangerang, melalui perancangan media tersebut diharapkan dapat menarik minat calon mahasiswa dan mahasiswi.
\end{abstract}

Kata kunci : Merchandise, Informasi, dan Promosi.

\section{ABSTRACT}

Merchandise is a form of a product that is intended as a means of information and promotion. High School Science Tarbiyah (ŠTíT) Islamic Village Tangerang is an educational institution of colleges oriented on the development of the Sciences of education. Every year in the high school Science Tarbiyah (ŠTÍT) Islamic Village Tangerang open pendaftran for prospective students and a new Sorority, which became the current problems, namely media promotion and information used by the high school Science Tarbiyah (ŠTíT) Islamic Village Tangerang still hasn't been fullest, as yet the availability of media merchandise. So the high school Science Tarbiyah (ŠTÍT) Islamic Village Tangerang need media merchandise in the form of pins, Sticker, Mug, Cap, Shopping Bag, calendars, umbrellas, and Pens. This research uses the software Adobe Illustrator CS6 which is a program supporting design. Very attractive design helps to maximize merchandising functions as a medium of information and promotion. Information message is disampakan either directly or visually. The promotion itself is a way to inform the public so that it can msyarakat interested in joining high school Science Tarbiyah (ŠTÍT) Islamic Village Tangerang. Research methodology method data collection and design concepts. We can deduce this research activity has a purpose and a goal to create a design media information in the form of merchandise are expected to enhance the image and 
interests of High School to join the Science of Tarbiyah (ŠTíT) Islamic Village Tangerang, through the design of the media is expected to attract prospective students and sophomores.

Keyword: Merchandise, information, and promotions.

\section{PENDAHULUAN}

Desain Komunikasi Visual dapat memberikan gambaran dan pandangan untuk menyampaikan informasi dengan menarik dan up to date. Dalam penyampaian informasi agar menarik minat para calon mahasiswa dan mahasiswi baru dibutuhkan media promosi agar maksud dan tujuan yang disampaikan dapat diterima oleh khalayak.

Sekolah Tinggi Ilmu Tarbiyah (STIT) Islamic Village adalah salah satu sekolah tinggi yang aktif di Tangerang yang bergerak dalam bidang pendidikan, serta berusaha untuk memberikan pelayanan terbaik sesuai dengan tuntutan ilmu yang semakin maju. Saat ini banyak Perguruan Tinggi lainnya yang bersaing dalam menarik minat calon mahasiswa dan mahasiswi baru setiap tahunnya.

Oleh sebab itu, Sekolah Tinggi Ilmu Tarbiyah (STIT) Islamic Village membutuhkan media sebagai sarana dalam memberikan informasi kepada calon mahasiswa dan mahasiswi baru, berupa media merchandise. Media merchandise sangatlah dibutuhkan sebagai penunjang promosi kepada calon mahasiswa dan mahasiswi baru agar dapat tertarik untuk bergabung pada Perguruan Tinggi tersebut.

Dengan menggunakan media merchandise dapat diyakini mudah untuk dilihat dan dimanfaatkan audience. Komunikasi visual merupakan salah satu cara penyampaian pesan secara visual, melalui sesuatu yang dapat dilihat, berupa gambar, ilustrasi, serta tulisan maupun jenis-jenis lainnya, dan pada prinsipnya selama pesan tersebut dapat dilihat.

Sekolah Tinggi Ilmu Tarbiyah (STIT) Islamic Village bergerak pada bidang pendidikan. Ingin meningkatkan citra dan minat para calon mahasiswa dan mahasiswi yang akan mendaftar, dan untuk mempromosikan sekolah tinggi tersebut kepada khalayak. Oleh sebab itu, Sekolah Tinggi Ilmu Tarbiyah (STIT) Islamic Village membutuhkan media merchandise untuk menarik minat calon mahasiswa dan mahasiswi baru serta memberikan informasi antara lain : Pin, Sticker, Mug, Topi, Shopping Bag, Kalender, Payung, dan Pulpen. Melalui media merchandise yang dirancang diharapkan akan membantu pihak Perguruan Tinggi dalam rangka mempromosikan dan menarik minat mahasiswa/i baru untuk bergabung di (STIT) Islamic Village, serta meningkatkan citra Perguruan Tinggi agar semakin dikenal masyarakat.

\section{PERMASALAHAN}

Setiap tahunnya di Sekolah Tinggi Ilmu Tarbiyah (STIT) Islamic Village Tangerang, membuka pendaftaran calon mahasiswa dan mahasiswi baru, yang diadakan secara rutin. Oleh sebab itu Sekolah Tinggi Ilmu Tarbiyah (STIT) Islamic Village, membutuhkan media promosi, berupa media merchandise. Pendaftaran calon mahasiswa dan mahasiswi baru biasanya membutuhkan informasi yang jelas dan terbaru serta membutuhkan sentuhan desain yang baru disetiap tahunnya, agar calon mahasiswa dan mahasiswi dapat tertarik untuk mengetahui informasi yang disampaikan, serta agar tertarik untuk bergabung pada perguruan tinggi tersebut. 


\section{LITERATURE REVIEW}

Literature review yang melandasi penelitian ini dengan mengacu pada penelitianpenelitian sebelumnya yaitu :

1. ANALISIS PENGARUH MERCHANDISE, ATMOSFIR DALAM GERAI, DAN PELAYANAN RITEL TERHADAP KEPUTUSAN PEMBELIAN (Studi kasus Pada Toserba Sogol Jaya Abadi Kec. Purwoasri), yang disusun oleh Septian Andini (11.1.02.02.0083), 2015. Merchandise berpengaruh signifikan terhadap keputusan pembelian pada konsumen Toserba Sogol Jaya Abadi Kec. Purwoasri. ${ }^{1}$

2. ANALISIS PENGARUH MERCHANDISE, PROMOSI, ATMOSFIR DALAM GERAI, PELAYANAN RITEL, DAN HARGA TERHADAP KEPUTUSAN PEMBELIAN (Studi Kasus pada Toko Buku Gramedia Pandanaran Kota Semarang), yang disusun oleh Muhammad Ikhwanuddin Muslim (C2A607105), 2011. Pengaruh promosi terhadap keputusan pembelian konsumen di toko buku Gramedia Pandanaran Kota Semarang. ${ }^{3}$

3. PERANCANGAN KOMUNIKASI VISUAL PROMOSI MERCHANDISE DENGAN MEREK INGENIOUS PROJECT, yang disusun oleh Grace Veronica Sompie, 2014. Sesuai dengan perkembangan zaman, semakin banyak produk baru bermunculan, khususnya di dunia bisnis online, yang memudahkan masyarakat untuk membeli segala sesuatu tanpa perlu beranjak dari tempatnya. Bahkan untuk menghadiahkan orang-orang tersayangnya, masyarakat pun dapat memesan produk yang mereka inginkan lewat online shop yang ada. Salah satu strategi yang perlu diperhatikan oleh para pemilik online shop adalah meningkatkan awareness-nya.

4. PENGARUH PROMOSI, ATMOSFER GERAI, DAN MERCHANDISE TERHADAP PEMBELIAN IMPULSIF PADA HARDY'S MALL GATSU DENPASAR, yang disusun oleh Tjokorda Istri Dwi Pradnyawati Pemayun dan Ni Wayan Ekawati, 2016. Promosi, atmosfer gerai, dan merchandise berpengaruh positif dan signifikan secara simultan terhadap pembelian impulsif di mana kegiatan promosi, atmosfer gerai, dan merchandise secara bersama-sama mempengaruhi pembelian impulsif pelanggan Hardy's Mall Gatsu Denpasar. ${ }^{6}$

5. NILAI BUDAYA DAYAK PADA DESAIN PRODUK FLEKSIBEL MERCHANDISE, yang disusun oleh Silvian Jati Putra, Akhirul Aminulloh, Sulih Indra Dewi, 2015. Presentasi budaya Dayak pada desain produk fleksibel Merchandise, terdapat pada desain yang secara umum mlalui tema atau kisah pada desain yang merupakan visualisasi dari tradisi, sejarah, dan kesenian suku Dayak. Serta secara khusus symbol-symbol yang terdapat didalam desain seperti, burung Enggang gading sebagai hewan endemik Kalimantan, motif tato, dan atribut adat mulai dari pakaian hingga peralatan yang digunakan oleh tokoh-tokoh dalam desain yang menjadi identitas dari suku Dayak. ${ }^{7}$

6. STUDI PENGARUH VISUAL MERCHANDISE UNTUK ANAK TERHADAP PERILAKU PEMBELIAN PAKET HAPPYMEAL DI RESTORAN MCDONALD'S SURABAYA, disusu oleh Listia Natadjaja, Rosaline Dewi F, Deddy Setyawan, 2011. Paket Happy Meal di Restoran Mcdonald's merupakan salah satu strategi promosi penjualan perusahaan, berupa pemberian merchandise mainan anak-anak di dalam paket menu makanan (premium offers). Bermula dari adanya ketertarikan peniliti terhadap aspek visual merchandise, strategi promosi penjualan, dan segmen anak yang saat ini cukup potensial untuk dikembangkan, penulis memutuskan untuk mengangkat fenomena sosial-ekonomi ini kedalam suatu penelitian ilmiah. ${ }^{4}$ 


\section{LANDASAN TEORI}

\section{Pengertian Media}

Media adalah sarana untuk menyimpan pesan atau informasi kepada public dengan menggunakan berbagai unsur komunikasi grafis seperti teks atau gambar atau foto. ${ }^{[3]}$

\section{Pengertian Desain}

Desain marupakan kegiatan perancanan arsitektur menitik beratkan pada perancangan yang mampu menjadi wadah bagi setiap aktifitas yang diperlukan. ${ }^{[9]}$

\section{Pengertian Desain Komunikasi Visual}

Desain grafis belakangan lebih sering disebut "Desain Komunikasi Visual" (DKV) karena memiliki peran mengomunikasikan pesan atau informasi kepada pembaca dengan berbagai kekuatan visual, seperti tipografi, ilustrasi warna, garis, layout dan sebagainya dengan bantuan teknologi. ${ }^{[11]}$

\section{Pengertian Warna}

Menurut Anggraini dan Kirana Nathalia, warna merupakan unsur penting dalam obyek desain. Dengan warna anda dapat menampilkan identitas atau citra yang ingin disampaikan. Baik dalam menyampaikan pesan atau membedakan sifat secara jelas. ${ }^{[2]}$

\section{Pengertian Promosi}

Promosi merupakan salah satu penentu keberhasilan suatu pemasaran. Pada hakikatnya promosi adalah suatu bentuk komunikasi pemasaran. Yang dimaksud dengan komunikasi pemasaran adalah aktvitas pemasaran yang berusaha menyebarkan informasi, mempengaruhi atau membujuk dan mengingatkan pasar sasaran atas perusahaan dan produknya agar bersedia menerima, membeli dan loyal pada produk yang ditawarkan perusahaan yang bersangkutan. ${ }^{[3]}$

\section{Pengertian Merchandise}

Visual merchandising melibatkan teknik yang tinggi dan unsur seni, seperti warna, tekstur, pencahayaan, mannequin, fixture, grafis, tanda petunjuk dan sebagainya.

Pegler dalam sumber yang sama menyatakan :

... the visual merchandiser is not selling any one piece

of merchandise, but rather the idea that any purchase from

that store will guarantee social success and the stamp of the

"right" taste level.

Artinya : gambar barang dagangan tidak menjual beberapa bagian dari barang dagangan, tapi melainkan tentang ide beberapa pembelian dari toko itu yang menjamin kesuksesan sosial dan tanda tentang tingkat selera yang tepat. ${ }^{[6]}$ 


\section{PEMBAHASAN}

\section{Perencanaan Media}

Memberikan informasi melalui media merchandise Sekolah Tinggi Ilmu Tarbiyah (STIT), berupa media komunikasi visual dapat digunakan sebagai alat pendukung penyampaian informasi dan promosi.

\section{Perencanaan Pesan (konsep kreatif)}

Perencanaan pesan atau konsep kreatif yang ingin di terapkan ke dalam media ini adalah sebuah ide kreatif yang berdasarkan dari data-data yang diperoleh di Sekolah Tinggi Ilmu Tarbiyah (STIT) Islamic Village, kemudian diolah menjadi sebuah rancangan yang menarik pada alur proses kreatif yang dilakukan pada setiap media sesuai dengan kebutuhan.

\section{Perencanaan Visual ( Konsp Visual)}

Ditampilkannya sketsa pada setiap rancangan media bertujuan agar mempermudah audience atau masyarakat supaya apa yang disampaikan efektif dan mudah diterima oleh masyarakat, serta membuat tampilan visual pada media terlihat lebih menarik.

\section{PROSES DESAIN}

\section{a. Layout Kasar}

Layout kasar adalah penerapan elemen-elemen desain media yang natinya akan dipergunakan dalam perancangan media komunikasi visual yang disertai acuan standarisasi pada desain yang akan dibuat, umumnya dibuat dengan tampilan hitam putih, dibuat dengan coretan atau sketsa dengan menggunakan pensil gambar. Layout kasar diperlukan, sebagai panduan pada saat proses desain dengan menggunakan aplikasi komputer. Berikut adalah gambar layout kasar proses desain media komunikasi visual.

- Pin

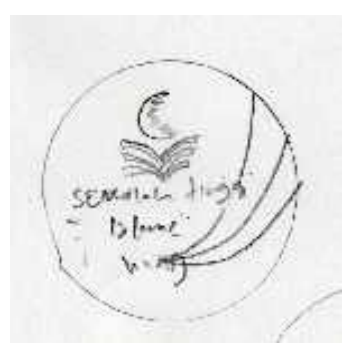

Gambar 1 Layout Kasar pin

Pada gambar 1 yaitu menggambarkan layout kasar pin yang digunakan sebagai media informasi pada Sekolah Tinggi Ilmu Tarbiyah (STIT) Islamic Village Tangerang. 
- Sticker

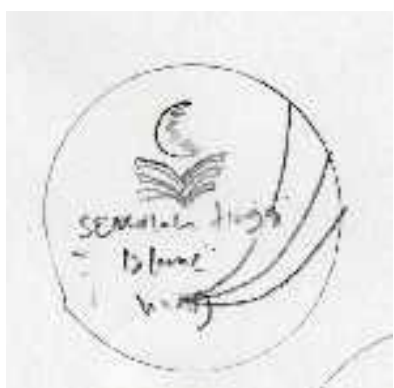

\section{Gambar 2 Layout Kasar Sticker}

Pada gambar 2 yaitu menggambarkan layout kasar sticker yang digunakan sebagai media infomasi pada Sekolah Tinggi Ilmu Tarbiyah (STIT) Islamic Village Tangerang.

- $M u g$

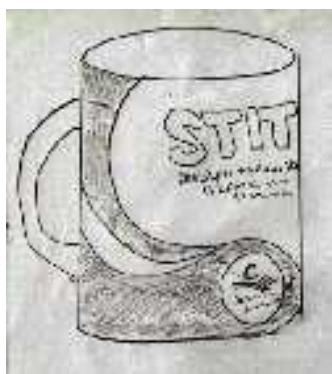

Gambar 3 Layout Kasar Mug

Pada gambar 3 yaitu menggambarkan layout kasar mug yang digunakan sebagai media informasi pada Sekolah Tinggi Ilmu Tarbiyah (STIT) Islamic Village Tangerang.

- Topi

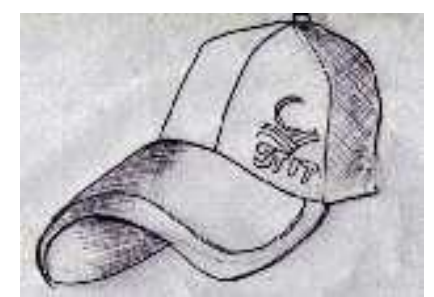

Gambar 4 Layout Topi

Pada gambar 4 yaitu menggambarkan layout kasar topi yang digunakan sebagai media informasi pada Sekolah Tinggi Ilmu Tarbiyah (STIT) Islamic Village Tangerang. 
- Shopping Bag

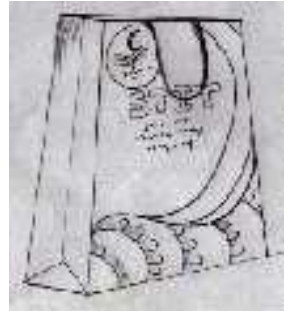

Gambar 5 Layout Kasar Shopping Bag

Pada gambar 5 yaitu menggambarkan layout kasar Shopping Bag yang digunakan sebagai media informasi pada Sekolah Tinggi Ilmu Tarbiyah (STIT) Islamic Village Tangerang.

- Kalender

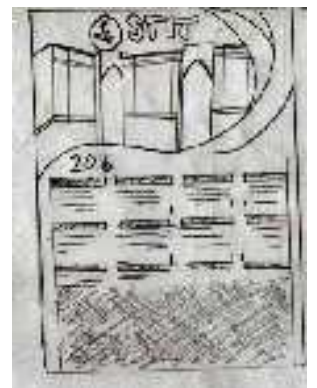

\section{Gambar 6 Layout Kasar Kalender}

Pada gambar 6 yaitu menggambarkan layout kasar Kalender yang digunakan sebagai media informasi pada Sekolah Tinggi Ilmu Tarbiyah (STIT) Islamic Village Tangerang.

- Payung

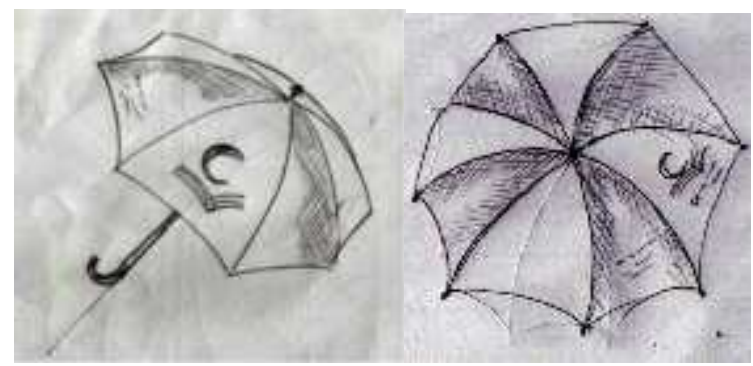

Gambar 7 Layout Kasar Payung

Pada gambar 7 yaitu menggambarkan layout kasar Payung yang digunakan sebagai media informasi pada Sekolah Tinggi Ilmu Tarbiyah (STIT) Islamic Village Tangerang.

- Pulpen

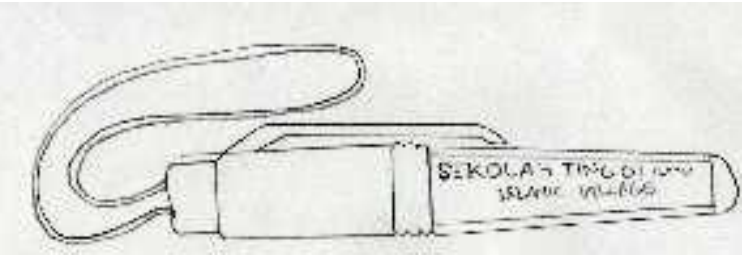

Gambar 8 Layout Kasar Pulpen 
Pada gambar 8 yaitu menggambarkan layout kasar Pulpen yang digunakan sebagai media informasi pada Sekolah Tinggi Ilmu Tarbiyah (STIT) Islamic Village Tangerang.

b. Layout Komprehensif

Layout Komprehensif adalah Proses desain yang sudah memasuki tahap komputerisasi dan pewarnaan, namun tahap ini belum selesai seluruhnya, karena masih harus mengalami proses revisi.

- Layout Komprehensif Pin

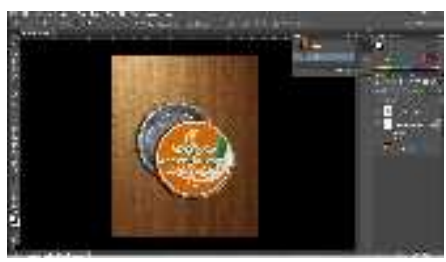

\section{Gambar 9. Layout Komprehensif Pin}

- Layout Komprehensif Sticker

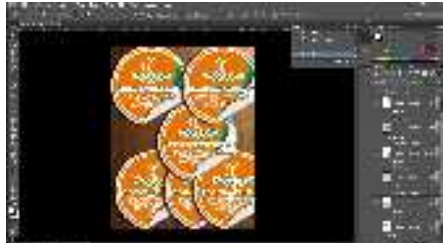

Gambar 10. Layout Komprehensif Sticker

- Layout Komprehensif Mug

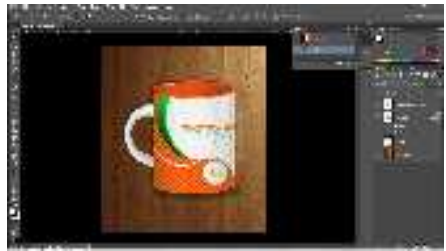

Gambar 11. Layout Komprehensif $M u g$

- Layout Komprehensif Topi

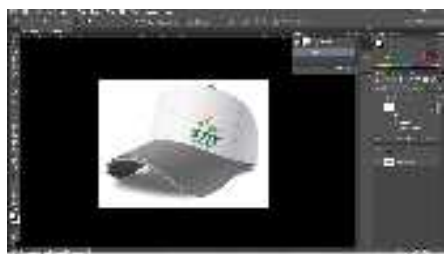

Gambar 12. Layout Komprehensif Topi 
- Layout Komprehensif Shopping Bag

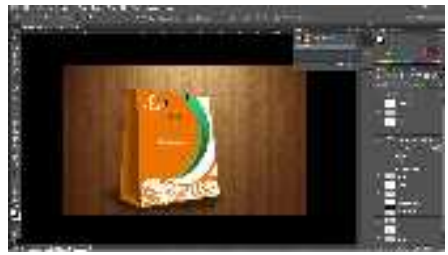

Gambar 13. Layout Komprehensif Shopping Bag

- Layout Komprehensif Kalender

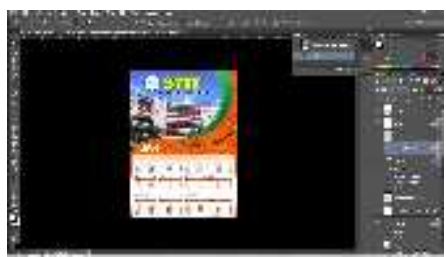

Gambar 14. Layout Komprehensif Kalender

- Layout Komprehensif Payung

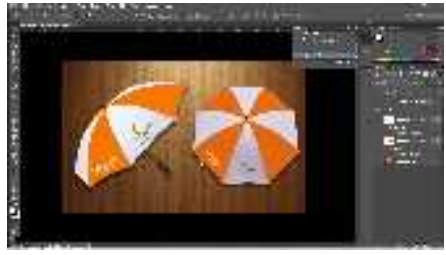

Gambar 15. Layout Komprehensif Payung

- Layout Komprehensif Pulpen

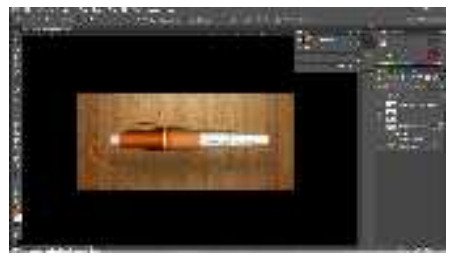

\section{Gambar 15. Layout Komprehensif Pulpen}

c. Final Artwork

Hasil akhir dari layout komprehensif yang telah diperbaiki, dimana tahap ini merupakan hasil akhir atau finishing, yang kemudian dapat digunakan untuk acuan saat proses produksi. 
- Pin

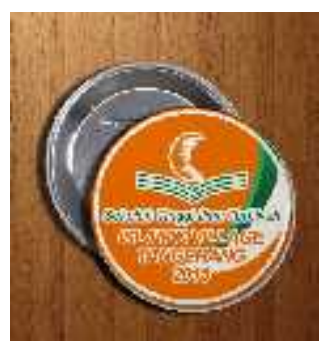

\section{Gambar 16. Final Artwork Pin}

Gambar 9 diatas menggamberkan hasil akhir yang telah finish berupa Mug ukuran 36 x 26 x 14cm dengan bahan Plano Khromo.

- Sticker

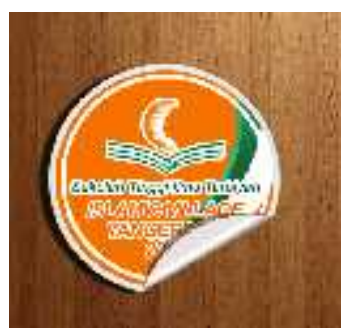

Gambar 17. Final Artwork Sticker

Gambar 10 diatas menggamberkan hasil akhir yang telah finish berupa Sticker ukuran $5 \mathrm{~cm}$ dengan bahan Kaleng.

- Mug

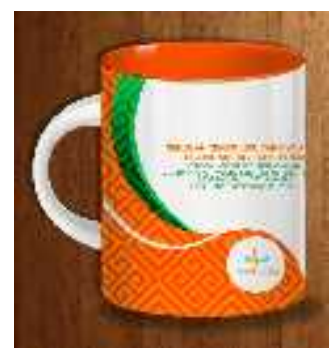

Gambar 18. Final Artwork Mug

Gambar 11 diatas menggamberkan hasil akhir yang telah finish berupa Mug dengan bahan Keramik Coating. 
- Topi

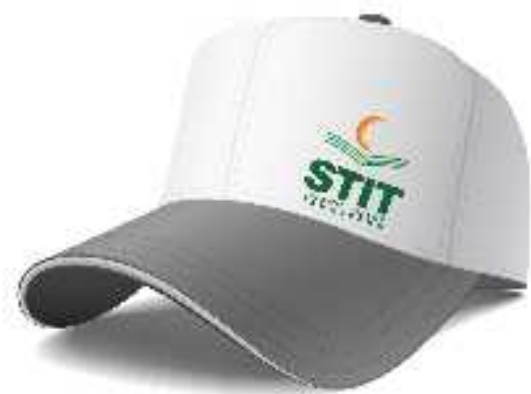

Gambar 19. Final Artwork Topi

Gambar 12 diatas menggamberkan hasil akhir yang telah finish berupa Topi ukuran All Size dengan bahan Canvas

- Shopping Bag

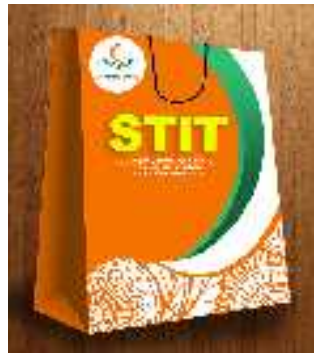

\section{Gambar 20. Final Artwork Shopping bag}

Gambar 13 diatas menggamberkan hasil akhir yang telah finish berupa Shopping bag ukuran

36 x 26 x 14cm dengan bahan Art Paper 150 gsm.

- Kalender

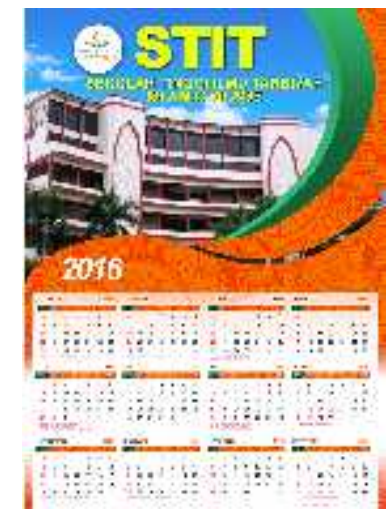

Gambar 21. Final Artwork Kalender

Gambar 16 diatas menggamberkan hasil akhir yang telah finish berupa kalender ukuran A3 (29,7 cm x $42 \mathrm{~cm})$ dengan bahan Art Carton 210gsm. 
- Payung

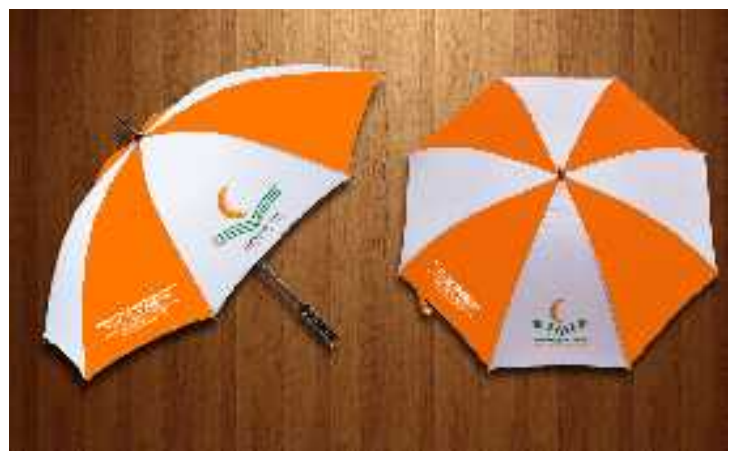

Gambar 22. Final Artwork Payung

Gambar 15 diatas menggamberkan hasil akhir yang telah finish berupa payung ukuran 21 Inchi diameter $(53,34 \mathrm{~cm})$ dengan bahan parasol fibergla.

- Pulpen

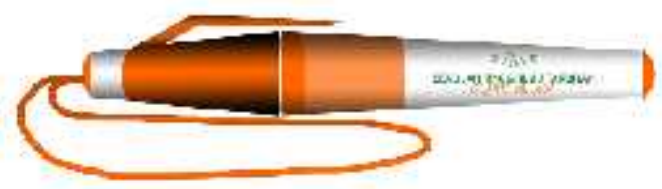

Gambar 23. Final Artwork Pulpen

Gambar 16 diatas menggamberkan hasil akhir yang telah finish berupa pulpen ukuran 13,5 cm dengan bahan Standart Pulpen.

\section{KESIMPULAN}

Desain komunikasi visual dalam sebuah kegitan sangatlah penting serta berguna dalam memperkenalkan image suatu lembaga instansi, serta dapat mensukseskan kegiatan yang berlangsung. Pada kegiatan penerimaan mahasiswa dan mahasiswi baru kali ini media yang diperlukan oleh Sekolah Tinggi Ilmu Tarbiyah (STIT) Islamic Village sebagai penunjang informasi dan promosi adalah barang kenang kenangan (merchandise) seperti: Amplop, Cover CD, Pin, Sticker, Mug, Topi, Shopping Bag, X-Banner, Kalender, Payung, Map Dosen, Memo, Piring Plakat, Jam, Pulpen. Media tersebut dipilih karena dapat menunjang informasi kegiatan yang diadakan oleh Sekolah Tinggi Ilmu Tarbiyah (STIT) Islamic Village. Media yang dirancang mempunyai daya tarik tersendiri dengan desain komunikasi visual yang menarik dan up to date sesuai pencitraan Sekolah Tinggi Ilmu Tarbiyah (STIT) Islamic Village sehigga dapat dijadikan daya tarik calon mahasiswa dan mahasiswi untuk mendapatkan informasi mengenai Sekolah Tinggi Ilmu Tarbiyah (STIT) Islamic Village. 


\section{DAFTAR PUSTAKA}

[1] Andini, Septian. 2015. Analisis Pengaruh Merchandise, Atmosfir Dalam Gerai, Dan Pelayanan Ritel Terhadap Keputusan Pembelian (Studi kasus Pada Toserba Sogol Jaya Abadi Kec.Purwoasri). KEDIRI : UNIVERSITAS NUSANTARA PGRI.

[2] Anggraini, Lia S dan Kirana Nathalia. 2014. Desain Komunikasi Visual. Bandung: Nuansa Cendekia.

[3] Maimunah, Lusyani Sunarya, Nina Larasati. 2012. Media Company Profile Sebagai Sarana Penunjang Informasi dan Promosi, Journal CCIT Vol.5 No.3, Tangerang: Perguruan Tinggi Raharja.

[4] Muslim, Muhammad Ikhwanuddin. 2011. Analisis Pengaruh Merchandise, Promosi, Atmosfir Dalam Gerai, Pelayanan Ritel, Dan Harga Terhadap Keputusan Pembelian (Studi Kasus pada Toko Buku Gramedia Pandanaran Kota Semarang). Semarang: Universitas Diponegoro.

[5] Natadjaja, Listia, Rosaline Dewi F, Deddy Setyawan. 2009. Studi Pengaruh Visual Merchandise Untuk Anak Terhadap Perilaku Pembelian Paket HappyMeal di Restoran McDonald's Surabaya, Jurnal Desain Komunikasi Visual Nirmana Vol 11, No 1. Surabaya: Universitas Kisten Petra.

[6] Pegler dalam Haiyan Hu dan Cynthia R. Jasper (2006 : 28 -29).

[7] Pemayun, Tjokorda Istri Dwi Pradnyawati, Ni Wayan Ekawati. 2016. Pengaruh Promosi, Atmosfer Gerai, Dan Merchandise Terhadap Pembelian Impulsif Pada Hardy's Mall Gatsu Denpasar, E-Jurnal ManajemenUnud, Vol. 5, No.7, Bali : Universitas Udayana.

[8] Putra, Silvian Jati, Akhirul Aminulloh, Sulih Indra Dewi, 2015. Nilai Budaya Dayak Pada Desain Produk Fleksibel Merchandise, JISIP (Jurnal Ilmu Sosial dan Ilmu Politik) Vol. 4 No. 1, Kota Malang : Universitas Tribhuwana Tunggadewi.

[9] Soepadmo Gatoet. 2013. Panduan Mudah Merancang Bangunan, Niaga Swadaya : Jakarta.

[10] Sompie, Grace Veronica. 2014. Perancangan Komunikasi Visual Promosi Merchandise Dengan Merek Ingenious Project, Jurnal DKV Adiwarna Vol 1, No 4, Surabaya: Universitas Kisten Petra.

[11] Supriyono dan Rakhmat. 2011. Desain Komunikasi Visual Teori dan Aplikasi, Andi: Yogyakarta. 